\title{
A Morphological Study on the Circle of Willis in the Dog
}

\author{
By \\ KUmiko TANUMA \\ The 2nd Department of Anatomy, Nippon Medical School, \\ Bunkyo-ku, Tokyo 113, Japan \\ (Director : Prof. F. Kikkawa) \\ - Received for Publication, March 25, 1981-
}

Key Words: Circle of Willis, Posterior cerebral artery, Dog, Silver impregnation.

Summary: The structure and variations of the circle of Willis in 55 days were studied from corrosion-cast specimens. The perivascular sympathetic innervation of the circle was also investigated in 9 dogs using the Schultz silver impregnation method. The following results were obtained.

1) The circle was entirely closed in all specimens.

2) The basic shape and variations of the circle were briefly as follows. (i) The connected shape of the bilateral anterior cerebral arteries could be classified into three types-having a common trunk $(87.3 \%$ ), having a single anterior communicating artery $(9.1 \%)$ and having a double anterior communicating artery (3.6\%). (ii) Asymmetry of the diameter of the anterior cerebral artery was found in $14.5 \%$.

(iii) Button-hole formation was observed in 1 case $(1.8 \%)$ in the posterior part of the circle on each side.

3) The patterns of divergence of the main cerebral arteries which arose from the circle were as follows. (i) The divergent patterns of the internal carotid artery could be classified into five types. The most general was a pattern which first gave off the posterior communicating artery, and secondly divided into the middle and anterior cerebral arteries. Such cases were found in $85.5 \%$ on the right side and $81.8 \%$ on the left. (ii) The position of origin of the anterior choroidal artery was from any of three arteries-the middle cerebral (right: $69.1 \%$, left: $67.3 \%$ ), the posterior communicating (right: $20.0 \%$, left: $23.6 \%$ ) and the internal carotid artery (right: $10.9 \%$, left: $9.1 \%$ ). (iii) Double posterior cerebral and anterior cerebellar arteries were found in $1.8 \%$ on the left side for the former and in $1.8 \%$ on each side for the latter.

4) The diameters of the main cerebral arteries were measured in $50 \mathrm{dogs}$ and a comparison was made of the diameters of the vessels on the right side with those on the left. In the dog, the diameter of the terminal branch of the basilar artery was slightly larger than that of the posterior communicating artery in $86.0 \%$ on the riright side and $94.0 \%$ on the left.

5) A correlation existed between the diameter of the posterior cerebral artery and that of the posterior communicating artery, and between the diameter of the pasterior cerebral artery and that of the terminal branch of the basilar artery.

6) The posterior cerebral artery was found to be innervated not by the sympa- 


\begin{abstract}
thetic nerve fibers from the stellate ganglion, but by those from the superior cervical ganglion.

The derivation of the posterior cerebral artery is discussed from the viewpoint of the perivascular sympathetic innervation in addition to the ontogenic and phylogenetic relations.
\end{abstract}

Numerous descriptions of the brain arteries and circle of Willis have been given for many mammals including man. However, few reports exist on the circle of Willis in dogs, so there is still ample room for further research.

The principal aims of this paper are: 1) to elucidate the detailed anatomical structure and variations of the dog circle, 2) to measure the component arteries, and 3) to describe the sympathetic innervation.

\section{Materials and Methods}

Sixty-four dogs were used. Acrylic resin was injected via the bilateral common carotid arteries in 55 cases. After injection, the heads were placed in $30 \%$ $\mathrm{KOH}$ solution to remove the soft tissues. The circle of Willis was removed from the other 9 dogs and immediately fixed in neutral formalin solution for 4 weeks. The circles were stained by the Schultz silver impregnation method. For reference, the circles of 40 human brains were also investigated.

\section{Observations}

I. Anatomical structure and variations in the cerebral arterial circle.

The component arteries of the cerebral arterial circle comprise the anterior cerebral and middle cerebral arteries in the anterior part, which are cranial divisions of the internal carotid artery; the posterior communicating and posterior cerebral arteries in the lateral part, which are caudal divisions of the internal carotid artery; and the terminal branch of the basilar artery and of the anterior cerebellar artery in the posterior part of the circle. In all the present specimens (55), the circle was entirely closed (Text-Fig. 1, Figs. 1-6)

The variations in shape of the circle were classified into three types, as indicated in Fig. 1a-g. The first was divided into three patterns according to the connected shape of tne bilateral anterior cerebral arteries. In the first pattern, the most normal shape, the anterior cerebral artries on both sides formed a common trunk (48 of 55 cases ; 87.3\%) (Text-Fig. 1a, Fig. 1). In the second pattern, the bilateral anterior cerebral arteries were connected by a single anterior communicating artery (5 cases; 9.1\%) (Text-Fig. 1b, Fig. 2). The third pattern possesed double anterior communicating arteries or formed an island between the left and right anterior cerebral arteries ( 2 cases; 3.6\%) (Text-Fig. 1c, Fig. 3).

The second type of variation in the anterior cerebral artery was a remarkable unilateral regression-asymmetry of the anterior cerebral artery. Such cases were observed in $8(14.5 \%)$ of the 55 specimens (Fig. 4). In 5 cases (9.1\%), the anterior cerebral artery on the left side was thicker than that on the right (Text-Fig. $1 \mathrm{~d})$, and in 3 cases (5.5\%) the right side was more strongly developed (Text-Fig. 1e).

The third variation was an island like a button-hole near the position of origin of the posterior cerebral artery in the posterior part of the circle. Such cases were found in $4(7.3 \%)$ of the 55 specimens -2 specimens on each side (TextFig. If and 1g, Fig. 6).

Many vascular variations exist in the ramifications or patterns of divergence of 


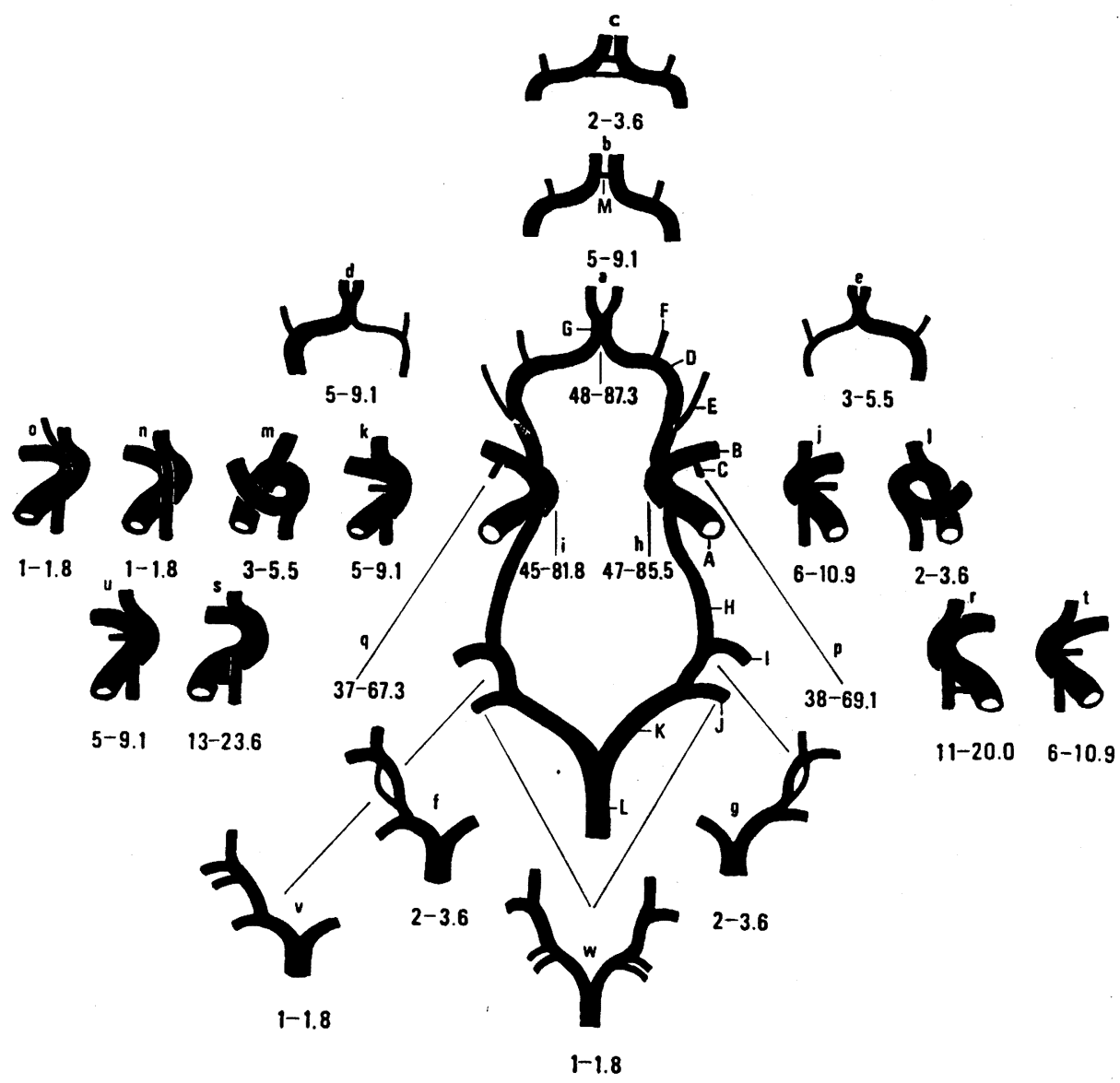

Text-Fig. 1. Variations of the cerebral arterial circle. The central figure shows the most general type of circle. In the scheme, the left number shows the case number and the right number shows its percentage. A : Internal carotid artery, B : middle cerebral artery, $\mathrm{C}$ : anterior choroidal artery, D : anterior cerebral artery, E : internal ophthalmic artery, F : internal ethmoidal artery, G : common trunk of the anterior cerebral artery, $\mathrm{H}$ : posterior communicating artery, I: posterior cerebral artery, $\mathrm{J}$ : anterior cerebellar artery, $\mathrm{K}:$ terminal branch of the basilar artery, $\mathrm{L}$ : basilar artery, $\mathrm{M}$ : anterior communicating artery. The variations are denoted by $\mathrm{a}-\mathrm{w}$.

the main cerebral arteries in the basal region. In particular, the divergent patterns of the internal carotid artery include numerous variations. The internal carotid artery divides into the anterior cerebral, middle cerebral, posterior communicating and anterior choroidal arteries. The divergent patterns by which these arteries arose from the internal carotid artery could be classified into five types as follows. In the first type, the most common, the internal carotid artery firstly gave off the posterior communicating artery, and secondly divided into the anterior cerebral and middle cerebral arteries. Such cases were found in 47 specimens $(85.5 \%)$ on the right side (Text-Fig. 1h) and 45 specimens (81.8\%) on the left (Text-Fig. 1i). The second type was not infrequently recognized. 
Here, the internal carotid artery from the proximal to the distal portion ramified into the posterior communicating and anterior choroidal arteries, and then separated into the anterior cerebral and middle cerebral arteries. Such cases were found in 6 specimens $(10.9 \%)$ on the right side (TextFig. $1 \mathrm{j}$ ) and 5 specimens $(9.1 \%)$ on the left (Text-Fig. 1k). In the third type, which was rarely found, the internal carotid artery firstly gave off the anterior cerebral artery and secondly branched into the middle cerebral and posterior communicating arteries. Such cases were observed in 2 specimens $(3.6 \%)$ on the right side (Text-Fig. 11) and 3 specimens $(5.5 \%)$ on the left (Text-Fig. $1 \mathrm{~m}$ ). The fourth and fifth types represented the rarest variations, each of which was found in one specimen $(1.8 \%)$ on the left side. In the fourth type, the internal carotid artery diverged into three channels at the same level-the anterior cerebral, middle cerebral and posterior communicating arteries (Text-Fig. 1n). In the fifth type, it gave off from its proximal to distal portion the posterior communicating and internal ophthalmic arteries, and ramified into the anterior cerebral and middle cerebral arteries (Text-Fig. 10).

The position of origin of the anterior choroidal artery also showed many variations like the internal carotid artery. It originated from one of three arteries: the middle cerebral, the posterior communicating or the internal carotid artery. The first type, originating $2-3 \mathrm{~mm}$ distal from the origin of the middle cerebral artery, was observed in 38 specimens $(69.1 \%)$ on the right side (Text-Fig. 1p) and 37 specimens $(67.3 \%)$ on the left (Text-Fig. 1q). The second type, arising from the posterior communicating artery at a position a iittle distal to its origin, was seen in 11 specimens $(20.0 \%)$ on the right side (Text-Fig. 1r) and 13 specimens (23.6\%) on the left (Text-Fig. 1s). The third type, arising from the internal carotid artery between the position of origin of the posterior communicating artery and the bifurcation of the anterior and middle cerebral arteries, was observed in 6 specimens $(10.9 \%)$ on the right side (Text-Fig. $1 \mathrm{t})$ and 5 specimens $(9.1 \%)$ on the left (Text-Fig. 1u).

The other variations or divergent patterns of the main cerebral arteries occurred in only a few specimens. They concerned the posterior cerebral, the anterior cerebellar and the internal opthalmic artery. Double posterior cerebral arteries were found in one specimen (1.8 $\%)$ on the left side (Text-Fig. 1v). Double anterior cerebellar arteries originated in one case each $(1.8 \%)$ on both sides (TextFig. 1w, Fig. 5). The internal ophthalmic artery generally arose from the anterior cerebral artery at a proximal position to the originating point, but in one specimen it derived from the internal carotid artery on the left side directly (Text-Fig. 10).

II. Measurements of the main cerebral arteries in the basal region.

The diameters of the arteries constituting the circle and originating from it were measured at their porximal portions in 50 specimens. The arteries surveyed were as follows: the internal carotid (the diameter being measured at the divergent portion of the cerebral arteries on the lateral side of the hypophysis), the vertebral (the diameter being measured at the proximal portion originating from the subclavian artery), the basilar (the diameter being measured at the portion bifurcating to the bilateral terminal branch of the basilar artery), the anterior cerebellar, the posterior cerebral, the posterior communicating, the middle cerebral, the anterior choroidal, the internal ophthalmic, the internal ethmoidal, the anterior cerebral, the common trunk of the anterior cerebral artery, the anterior communi- 
cating and the cerebrospinal artery. A comparison of the values for the diameters of the arteries on the right side with those on the left is given in Table 1. With the exception of the internal ethmoidal artery, the values for the diameters of all arteries on the left side were higher than those for the arteries on the right. In particular, the diameters of the posterior communicating and the middle cerebral artery on the left side were about 4 times those on the right. Arteries of the same diameter on both sides amounted to from 10 to $26 \%$. The percentage of ill specimens represents cases in which the arteries on both sides could not be compared because the contralateral artery was injured.

Table 2 gives average values for the diameters of the main cerebral arteries. The data indicate that the diameter of the internal ethmoidal artery on the right side was larger than that on the left, as in Table 1.

A comparison was made between the individual diameters of the posterior communicating artery and those of the terminal branch of the basilar artery, in order to study the stream of blood flowing into the posterior cerebral artery. A correlation between the posterior cerebral artery and the two above arteries was then undertaken to assess whether the diameter of the posterior cerebral artery is affected by the terminal branch of the brsilar artery or by the posterior communicating artery. Table 3 lists the mearured values of the individual diameters of the terminal branch of the basilar artery, the posterior cerebral artery and the posterior communicating artery in 50 specimens. The diameter of the posterior communicating artery was larger than that of the terminal branch of the basilar artery in 1 specimen $(2.0 \%)$ on the right side and in 2 specimens $(4.0 \%)$ on the left. These two arteries were of the same size in 4 specimens $(8.0 \%)$ on the right side and 1 specimen $(2.0 \%)$ on the left. In 2 specimens $(4.0 \%)$, they could not be compared because of injury on the right side. In all other specimens, i.e. 43 speci-

Talbe 1. A comparison of size

\begin{tabular}{lcccc}
\hline & Right larger & Left larger & Equal & ill specimen \\
\hline A. carot. int. & 22.0 & 52.0 & 26.0 & 0 \\
A. vertebr. & 30.0 & 34.0 & 16.0 & 20.0 \\
A. cerebrosp. & 26.0 & 38.0 & 20.0 & 16.0 \\
A. basil. & 24.0 & 52.0 & 22.0 & 2.0 \\
A. cereb. ant. & 18.0 & 38.0 & 34.0 & 10.0 \\
A. cer. post. & 20.0 & 54.0 & 22.0 & 4.0 \\
A. comm. post. & 16.0 & 60.0 & 22.0 & 2.0 \\
A. cer. med. & 16.0 & 60.0 & 20.0 & 4.0 \\
A. chor. ant. & 32.0 & 34.0 & 14.0 & 20.0 \\
A. cer. ant. & 24.0 & 58.0 & 20.0 & 0 \\
A. ophth. int. & 22.0 & 46.0 & 10.0 & 22.0 \\
A. ethm. int. & 42.0 & 40.0 & 12.0 & 6.0 \\
\hline
\end{tabular}

A comparison of the value of the diameters of the arteries on the right side with those on the left in $50 \mathrm{dogs}$ is shown in percentages. The A. basilaris in Table 1 is the terminal branch of the basilar artery. 
Table 2. The average value of the diameters of the main cerebral arteries in 50 dogs $(\mathrm{cm})$.

\begin{tabular}{lcc}
\hline & Right & Left \\
\hline A. carot. int. & $0.151(0.120-0.195)$ & $0.156(0.125-0.200)$ \\
A. vertebr. & $0.210(0.115-0.300)$ & $0.212(0.135-0.300)$ \\
A. cerebrosp. & $0.138(0.100-0.225)$ & $0.141(0.100-0.225)$ \\
A. basil (terminalis) & $0.123(0.080-0.170)$ & $0.127(0.090-0.175)$ \\
A. bereb. ant. & $0.091(0.040-0.120)$ & $0.093(0.050-0.130)$ \\
A. cer. post. & $0.110(0.080-0.140)$ & $0.116(0.090-0.150)$ \\
A. comm. post. & $0.098(0.070-0.135)$ & $0.105(0.080-0.140)$ \\
A. cer. med. & $0.132(0.100-0.175)$ & $0.138(0.100-0.180)$ \\
A. chor. ant. & $0.056(0.035-0.095)$ & $0.057(0.035-0.095)$ \\
A. ophth. int. & $0.055(0.030-0.090)$ & $0.059(0.030-0.090)$ \\
A. ethm. int. & $0.062(0.035-0.095)$ & $0.061(0.030-0.085)$ \\
A. cer. ant. & $0.110(0.075-0.145)$ & $0.119(0.080-0.180)$ \\
A. comm. ant. & $0.094(0.090-0.130)$ \\
A. basil. & $0.147(0.100-0.185)$ \\
\hline
\end{tabular}

The value in parentheses shows the individual minimum and maximum value.

Table 3. The measured value of the terminal branch of the basilar artery, the posterior communicating and the posterior cerebral artery in the dog $(\mathrm{cm})$.

\begin{tabular}{|c|c|c|c|c|c|c|c|c|c|c|c|c|c|}
\hline \multirow[b]{2}{*}{ No. } & \multicolumn{2}{|c|}{ A. basil. } & \multicolumn{2}{|c|}{$\begin{array}{l}\text { A. comm. } \\
\text { post. }\end{array}$} & \multicolumn{2}{|c|}{$\begin{array}{l}\text { A. cer. } \\
\text { post. }\end{array}$} & \multirow[b]{2}{*}{ No. } & \multicolumn{2}{|c|}{ A. basil. } & \multicolumn{2}{|c|}{$\begin{array}{l}\text { A. comm. } \\
\text { post. }\end{array}$} & \multicolumn{2}{|c|}{$\begin{array}{l}\text { A. cer. } \\
\text { post. }\end{array}$} \\
\hline & $\mathrm{R}$ & $\mathrm{L}$ & $\mathrm{R}$ & $\mathrm{L}$. & $\mathrm{R}$ & $\mathrm{L}$ & & $\mathrm{R}$ & $\mathrm{L}$ & $\mathrm{R}$ & $\mathrm{L}$ & $\mathrm{R}$ & $\mathrm{L}$ \\
\hline 1. & 0.125 & 0.130 & 0.100 & 0.110 & 0.100 & 0.100 & 26. & 0.135 & 0.130 & 0.100 & 0.085 & 0.100 & 0.100 \\
\hline 2. & 0.100 & 0.110 & 0.090 & 0.090 & 0.100 & 0.100 & 27. & 0.100 & 0.105 & 0.060 & 0.080 & 100 & 0.100 \\
\hline 3. & 0.135 & 0.135 & 0.110 & 0.100 & 0.110 & 0.125 & 28. & 0.115 & 0.110 & 0.085 & 0.085 & 0.110 & 90 \\
\hline 4. & 0.130 & 0.135 & - & 0.120 & - & 0.120 & 29. & 0.150 & 0.160 & 0.110 & 0.135 & 0.110 & 0.140 \\
\hline 5. & 0.135 & 0.130 & 0.120 & 0.140 & 0.130 & 0.115 & 30. & 0.125 & 0.120 & 0.105 & 0.100 & 0.120 & 0.095 \\
\hline 6. & 0.115 & 0.120 & 0.100 & 0.085 & 0.120 & 0.110 & 31. & 0.100 & 0.130 & 0.080 & 0.095 & 0.100 & 0.100 \\
\hline 7. & 0.150 & 0.145 & 0.135 & 0.140 & 0.120 & 0.150 & 32. & 0.125 & 0.125 & 0.090 & 0.095 & 0.115 & 0.120 \\
\hline 8. & 0.125 & 0.125 & 0.100 & 0.100 & 0.105 & 0.100 & 33. & 0.120 & 0.135 & 0.100 & 0.095 & 0.100 & 0.115 \\
\hline 9. & 0.145 & 0.130 & 0.100 & 0.100 & 0.125 & 0.135 & 34. & 0.100 & 0.100 & 0.090 & 0.095 & 0.125 & 0.100 \\
\hline 10. & - & 0.105 & 0.080 & 0.090 & - & 0.110 & 35. & 0.130 & 35 & 0.110 & 0 & 35 & 0.140 \\
\hline 11. & 0.095 & 0.130 & 0.075 & 0.095 & 0.115 & 0.1 & 36. & 0.130 & 35 & 0.110 & 0 & 10 & 0.120 \\
\hline 12. & 0.120 & 0.125 & 0.085 & 0.095 & 0.100 & 0. & 7. & 0.100 & 0. & 00 & 0 & & 0.120 \\
\hline 13. & 0.160 & 0.145 & 0.110 & 0.130 & 0.135 & 0.135 & 38. & 0.110 & 0.100 & 0.100 & 0.120 & 10 & 0.120 \\
\hline 14. & 0.130 & 0.140 & 0.110 & 0.110 & 0.115 & 0.130 & 39. & 0.100 & 0.130 & 0.100 & 0.100 & 0.095 & 0.100 \\
\hline 15. & 0.120 & 0.130 & 0.100 & 0.110 & 0.100 & 0.125 & 40. & 0.110 & 0.120 & 0.090 & 0.100 & 0.110 & 0.120 \\
\hline 16. & 0.145 & 0.155 & 0.090 & 0.105 & 0.110 & 0.12 & 41. & 0.080 & 0.090 & 0.070 & 0.080 & 0.090 & 0.095 \\
\hline 17. & 0.160 & 0.165 & 0.100 & 0.120 & 0.125 & 0.12 & 42. & 0.100 & 0.100 & 0.080 & 0.080 & 0.100 & 0.090 \\
\hline 18. & 0.085 & 0.180 & 100 & 0.110 & 0.105 & 0.110 & 43. & 0.120 & 0.130 & 0.085 & 0.085 & 0.080 & 0.100 \\
\hline 19. & 0.110 & 0.130 & ( & 0.125 & 0.100 & 0.12 & 44. & 0.100 & 0.100 & 0.080 & 0.090 & 0.095 & 0.100 \\
\hline 20. & 0.150 & 0.150 & 0.120 & 0.130 & 0.115 & 0.125 & 45. & 130 & 130 & 0.100 & 0.100 & 0.100 & 0.085 \\
\hline 21. & 0.1308 & 0.140 & c & 0 & 0.120 & $\begin{array}{l}0.100 \\
0.095\end{array}$ & xo. & 0.120 & 0.130 & 0.100 & 0.110 & 0.100 & 0.110 \\
\hline 22. & 0.135 & 0.12 & 0.095 & 0.1 & 0.100 & 0.10 & 47. & 0.110 & 0. & 0.080 & 0.0 & 0.090 & 0.090 \\
\hline 23. & 0.145 & 0.135 & 0.115 & 0.120 & 0.1 & 0.10 & 48. & 0.095 & 0.100 & 0.095 & 0.095 & 0.095 & 0.110 \\
\hline 24. & 0.170 & 0.175 & 0.130 & 0.140 & 0.140 & 0.130 & 49. & 0.150 & 0.140 & 0.120 & 0.100 & 0.120 & 0.125 \\
\hline 25. & 0.135 & 0.135 & 0.100 & 0.120 & 0.125 & 0.125 & 50. & 0.120 & 0.120 & 0.100 & 0.095 & 0.120 & 0.120 \\
\hline
\end{tabular}


mens $(86.0 \%)$ on the right side and 47 specimens $(94.0 \%)$ on the left, the diameter of the terminal branch of the basilar artery was larger than that of the posterior communicating artery.

On the whole, the diameter of the terminal branch of the basilar artery was larger than that of the posterior communicating artery on both sides. The difference ranged from $0.005 \mathrm{~cm}$ to $0.060 \mathrm{~cm}$, with a mean of $0.028 \mathrm{~cm}$ on the right side and $0.025 \mathrm{~cm}$ on the left. In the specimens in which the diameter of the posterior communicating artery was larger than that of the terminal branch of the basilar artery, the difference ranged from 0.010 $\mathrm{cm}$ to $0.020 \mathrm{~cm}$ with a mean of $0.015 \mathrm{~cm}$.

In the 50 investigated dogs, a correlation existed between the diameter of the posterior cerebral artery and that of the posterior communicating artery on both sides. The coefficient of correlation, with confidence limits of 95 to $99 \%$ on both sides, was 0.58 on the right side and 0.62 on the left. A correlation also existed between the diameter of the posterior cerebral arteay and that of the terminal branch of the basilar artery. The correlation cofficient was 0.60 on the right side and 0.52 on the left with the same reliability as in the above case.

For reference, the diameters of human arteries in similar positions were measured in 40 specimens, and the values obtained are shown in Table 4 . In the case of man, the difference in the diameters of

Table 4. The measured value of the diameter of the terminal branch of the basilar artery, the posterior communicating and the posterior cerebral artery in man $(\mathrm{cm})$.

\begin{tabular}{|c|c|c|c|c|c|c|c|c|c|c|c|c|c|}
\hline \multirow[b]{2}{*}{ No. } & \multicolumn{2}{|c|}{ A. basil. } & \multicolumn{2}{|c|}{$\begin{array}{l}\text { A. comm. } \\
\text { post. }\end{array}$} & \multicolumn{2}{|c|}{$\begin{array}{l}\text { A. cer. } \\
\text { post. }\end{array}$} & \multirow[b]{2}{*}{ No. } & \multicolumn{2}{|c|}{ A. basil. } & \multicolumn{2}{|c|}{$\begin{array}{l}\text { A. comm. } \\
\text { post. }\end{array}$} & \multicolumn{2}{|c|}{$\begin{array}{l}\text { A. cer. } \\
\text { post. }\end{array}$} \\
\hline & $\mathrm{R}$ & $\mathrm{L}$ & $\mathrm{R}$ & $\mathrm{L}$ & $\mathrm{R}$ & $\mathrm{L}$ & & $\mathrm{R}$ & $\mathrm{L}$ & $\mathrm{R}$ & $\mathrm{L}$ & $\mathrm{R}$ & $\mathrm{L}$ \\
\hline 1. & 0.22 & 0.13 & 0.14 & 0.28 & 0.29 & 0.27 & 21. & 0.20 & 0.18 & 0.08 & 0.08 & 0.20 & 0.18 \\
\hline 2. & 0.08 & 0.12 & 0.28 & 0.30 & 0.28 & 0.30 & 22 . & 0.21 & 0.21 & 0.08 & 0.08 & 0.21 & 0.21 \\
\hline 3. & 0.16 & 0.22 & 0.24 & 0.28 & 0.22 & 0.24 & 23. & 0.20 & 0.14 & 0.03 & 0.03 & 0.20 & 0.16 \\
\hline 4. & 0.10 & 0.12 & 0.20 & 0.22 & 0.25 & 0.20 & 24. & 0.25 & 0.25 & 0.08 & 0.08 & 0.17 & 0.22 \\
\hline 5. & 0.20 & 0.06 & 0.10 & 0.25 & 0.18 & 0.22 & 25. & 0.22 & 0.20 & 0.09 & 0.17 & 0.21 & 0.22 \\
\hline 6. & 0.24 & 0.13 & 0.05 & 0.20 & 0.20 & 0.19 & 26. & 0.23 & 0.23 & 0.08 & 0.06 & 0.24 & 0.20 \\
\hline 7. & 0.19 & 0.19 & 0.20 & 0.21 & 0.25 & 0.25 & 27. & 0.10 & 0.22 & 0.22 & 0.05 & 0.23 & 0.23 \\
\hline 8. & 0.25 & 0.14 & 0.06 & 0.22 & 0.26 & 0.27 & 28. & 0.22 & 0.21 & 0.08 & 0.08 & 0.21 & 0.22 \\
\hline 9. & 0.24 & 0.24 & 0.09 & 0.08 & 0.24 & 0.24 & 29. & 0.29 & 0.27 & 0.08 & 0.08 & 0.23 & 0.27 \\
\hline 10 & 0.30 & 0.20 & 0.17 & 0.17 & 0.30 & 0.30 & 30. & 0.17 & 0.13 & 0.13 & 0.18 & 0.18 & 0.15 \\
\hline 11. & 0.27 & 0.27 & 0.03 & 0.03 & 0.22 & 0.22 & 31. & 0.24 & 0.25 & 0.06 & 0.05 & 0.22 & 0.20 \\
\hline 12. & 0.12 & 0.13 & 0.13 & 0.07 & 0.17 & 0.13 & 32. & 0.25 & 0.20 & 0.07 & 0.07 & 0.14 & 0.19 \\
\hline 13. & 0.35 & 0.32 & 0.09 & 0.10 & 0.35 & 0.32 & 33. & 0.17 & 0.15 & 0.12 & 0.12 & 0.17 & 0.17 \\
\hline 14. & 0.20 & 0.09 & 0.10 & 0.20 & 0.20 & 0.17 & 34. & 0.18 & 0.18 & 0.07 & 0.07 & 0.17 & 0.22 \\
\hline 15. & 0.21 & 0.08 & 0.09 & 0.19 & 0.20 & 0.20 & 35. & 0.27 & 0.27 & 0.08 & 0.07 & 0.26 & 0.23 \\
\hline 16. & 0.11 & 0.08 & 0.17 & 0.18 & 0.19 & 0.16 & 36. & 0.24 & 0.27 & 0.06 & 0.05 & 0.20 & 0.21 \\
\hline 17. & 0.17 & 0.19 & 0.18 & 0.12 & 0.28 & 0.28 & 37. & 0.09 & 0.17 & 0.25 & 0.14 & 0.24 & 0.23 \\
\hline 18. & 0.15 & 0.19 & 0.06 & 0.06 & 0.20 & 0.19 & 38. & 0.18 & 0.15 & 0.13 & 0.15 & 0.22 & 0.21 \\
\hline 19. & 0.24 & 0.24 & 0.08 & 0.07 & 0.22 & 0.22 & 39. & 0.09 & 0.26 & 0.30 & 0.05 & 0.30 & 0.26 \\
\hline 20. & 0.20 & 0.20 & 0.06 & 0.05 & 0.20 & 0.20 & 40. & 0.29 & 0.30 & 0.08 & 0.07 & 0.28 & 0.28 \\
\hline
\end{tabular}


these two arteries showed extremely high values compard with those of the dog. That is to sag, the diameter of the terminal branch of the basilar artery was larger than that of the posterior communicating artery in 29 specimens $(72.5 \%)$ on the right side and 27 cases $(67.5 \%)$ on the left. In these cases, the difference in diameters of the two arteries ranged from $0.040 \mathrm{~cm}$ to $0.260 \mathrm{~cm}$, with a mean of $0.146 \mathrm{~cm}$ on the right side and $0.140 \mathrm{~cm}$ on the left. The diameter of the posterior communicating artery was larger than that of the terminal branch of the basilar artery in 10 cases $(25.0 \%)$ on the right side and 12 cases $(30.0 \%)$ on the left. In these cases, the difference in the arteries ranged from $0.010 \mathrm{~cm}$ to $0.210 \mathrm{~cm}_{\mathrm{c}}$ with an average of $0.096 \mathrm{~cm}$ on the right side and $0.102 \mathrm{~cm}$ on the left. In one specimen $(2.5 \%)$, these arteries were of the same size only on the right side.

In the 40 human specimens, a correlation was found between the diameter of the posterior cerebral artery and that of the posterior communicating artery on the right side, and between the diameter of the terminal branch of the basilar artery and that of the posterior cerebral artery on the left. The coefficient of the former correlation was 0.34 and that of the latter was 0.37 with a reliability of 95 to $99 \%$. The diameter of the posterior cerebral artery was not correlated with that of the terminal branch of the basilar artery on the right side. The posterior cerebral artery was not correlated with the posterior communicating artery on the left also.

III. Sympathetic innervation of the circle and the origin of the posterior cerebral artery.

The perivascular sympathetic nerve fibers of the vertebral artery originate from the stellate ganglion. They run in the cranial direction and extend anteriorly accompanying the basilar artery. The plexus of these nerve fibers is distributed to each of the branches of the basilar artery to form a network of loose nerve fibers around the vessels. These loose nerve fibers which are distributed to the terminal branch of the basilar artery were traced to the anterior cerebellar artery and approached the origin of the posterior cerebral artery, but did not supply the posterior cerebral artery (Text-Fig. 2, Nos. 1-9, Fig. 7). On the other hand, the sympathetic nerve fibers around the internal carotid artery originate from the superior cervical ganglion. These fibers supply the anterior cerebral, the middle cerebral and the anterior choroidal artery to form a complex network around these vassels. Each of the filaments anastomoses with contralateral ones at the common trunk of the anterior cerebral artery in the anterior part of the circle. The thick bundle from the intricated network runs backwards, being accompanied by the posterior communicating artery. These fibers supplied the posterior cerebral artery to divide into several fibers near its origin (Text-Fig. 2, Fig. 7). Moreover, the fibers ran backwards and could be traced to the near portion of the origin of the anterior cerebellar artery (Text-Fig. 2, Fig. 7). In 3 cases on the right side (Text-Fig. 2, Nos. 1-3) and in 6 on the left (Text-Fig. 2, Nos. 2-5, 7-8) among 9 cases examined on both sides, there was a communication between the terminal nerve fibers from the vertebral plexus and the posterior flows of the perivascular internal carotid plexus (Table 5).

\section{Discussion}

It has been stated by Moffat (1961) of the rat embryo, by Kaplan \& Ford (1966) of the human embryo and by Tanuma (1978) of the chick and pig embryos, that the cerebral arterial circle is formed in 
A Morphological Study on the Circle of Willis in the Dog

163

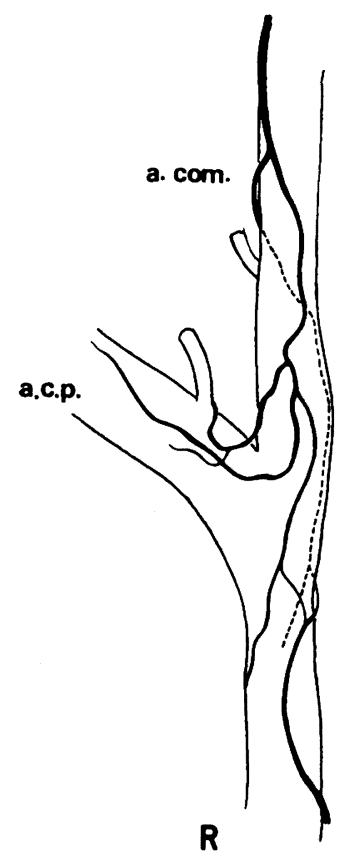

NO. I

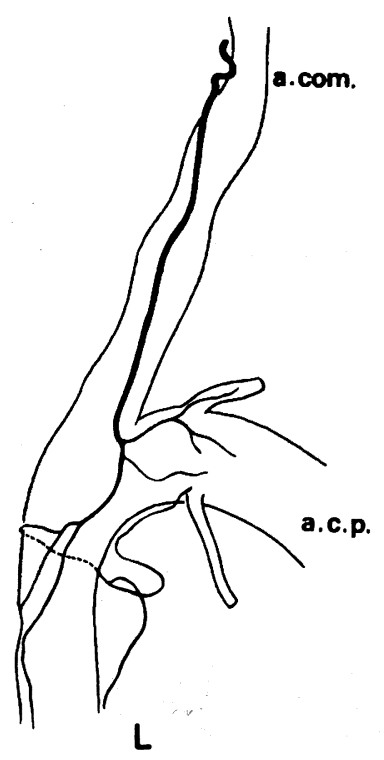

NO. 2
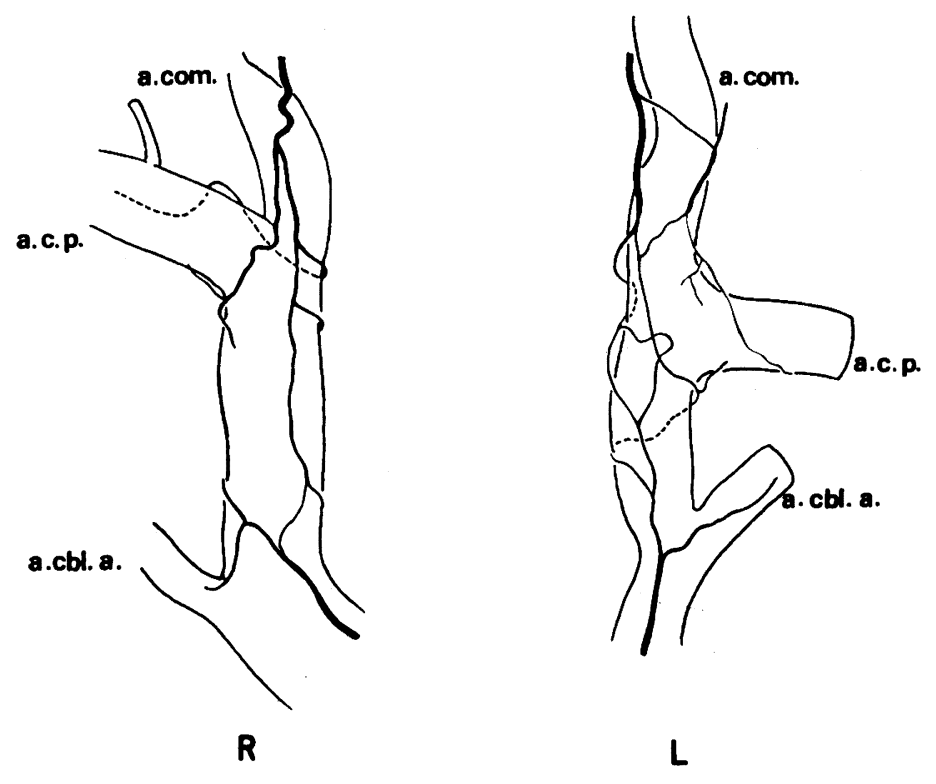

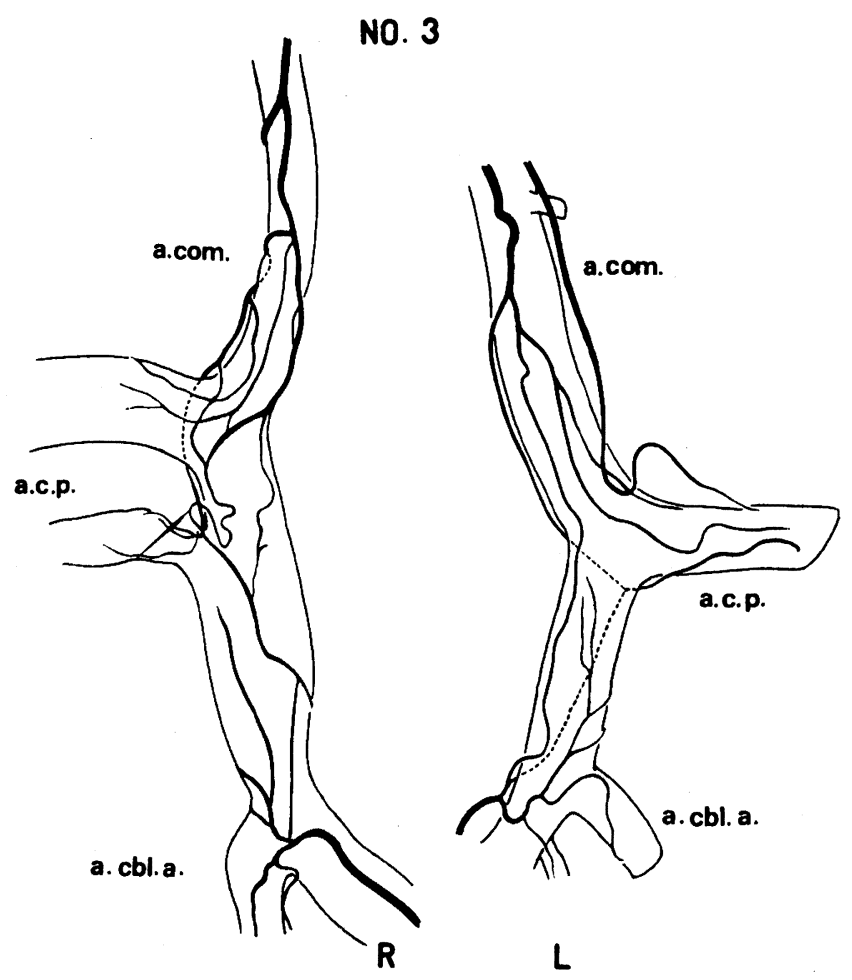

NO. 4

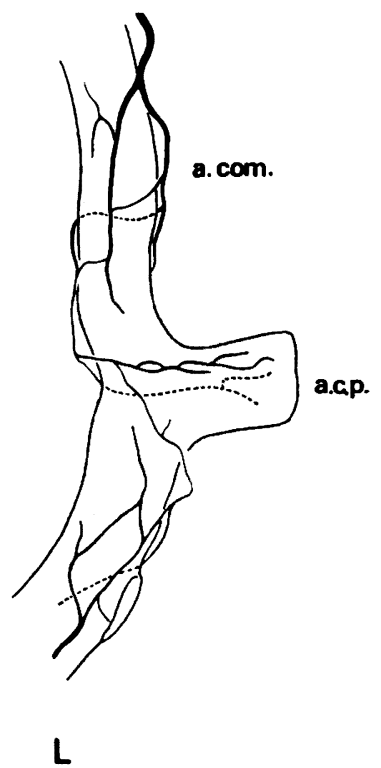

NO. 5

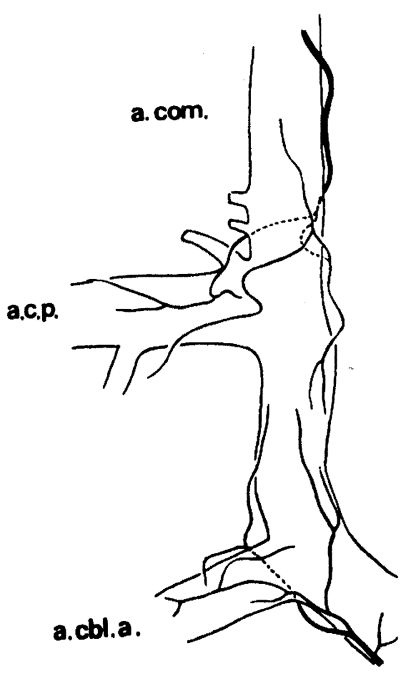

$\mathbf{R}$

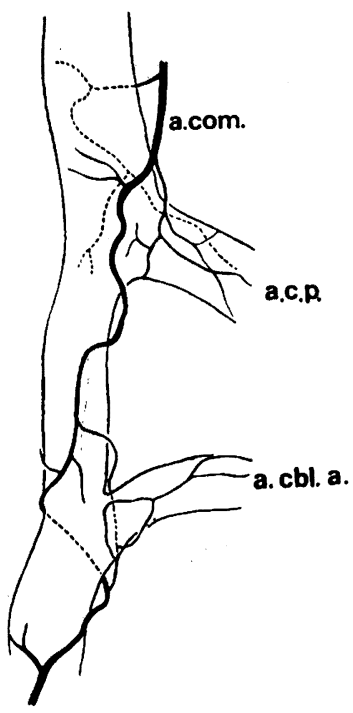

L 
A Morphological Study on the Circle of Willis in the Dog

165

NO. 6

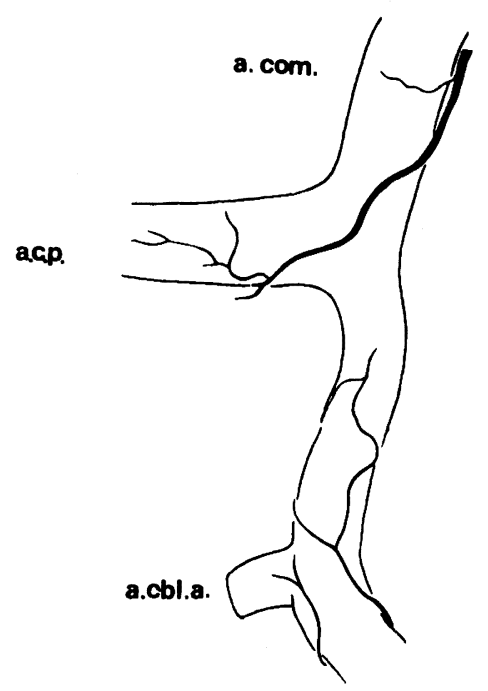

R

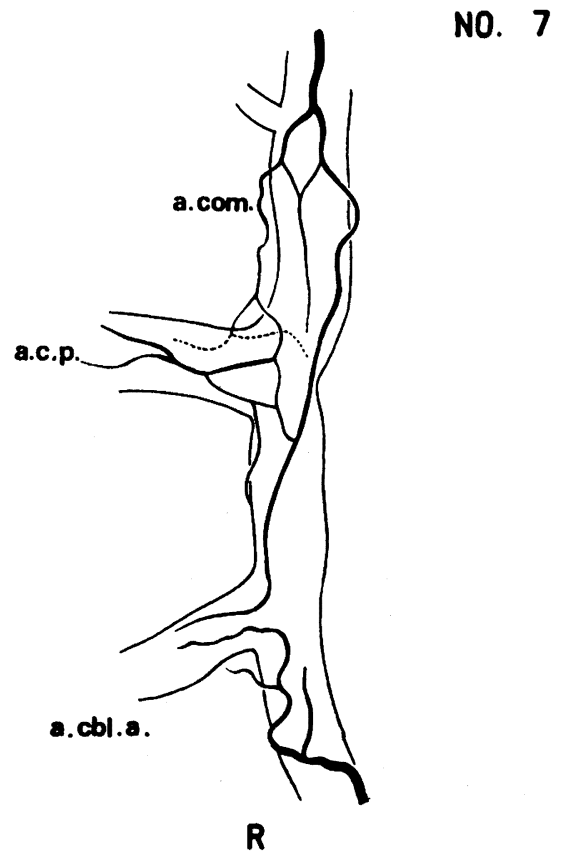

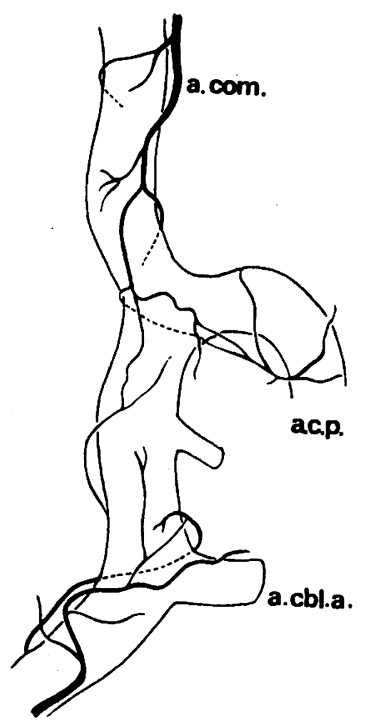

L

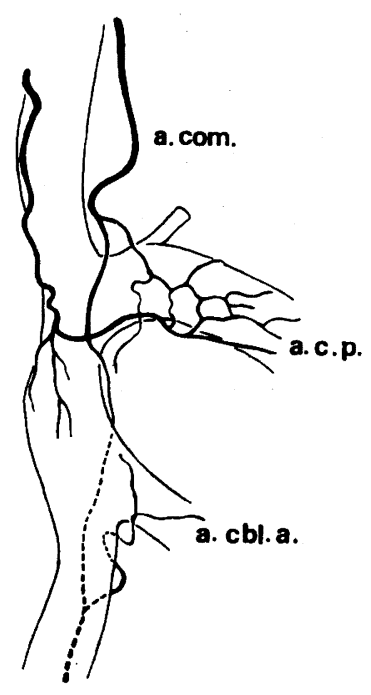

L 
NO. 8

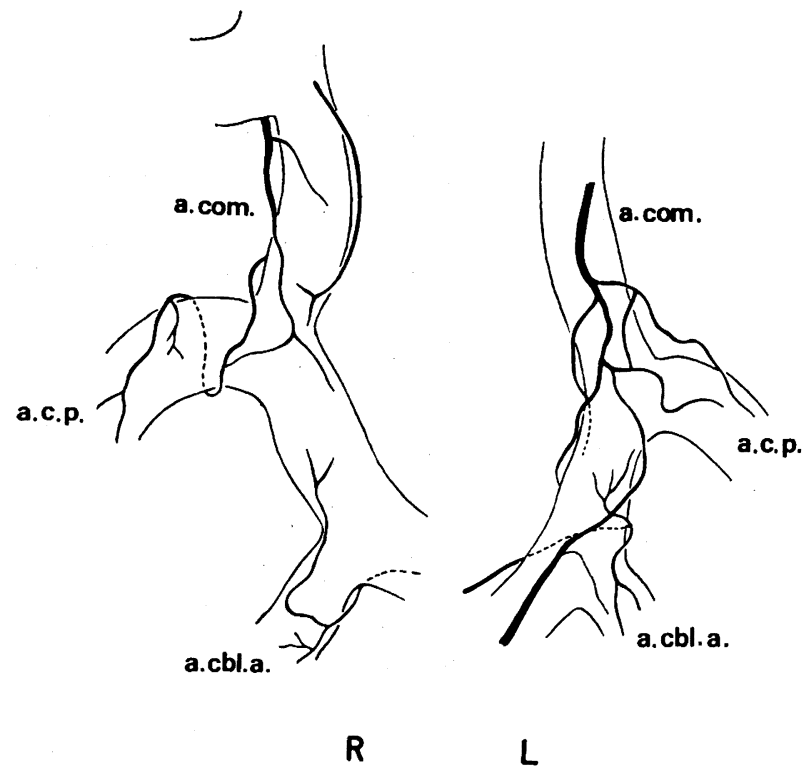

N0. 9

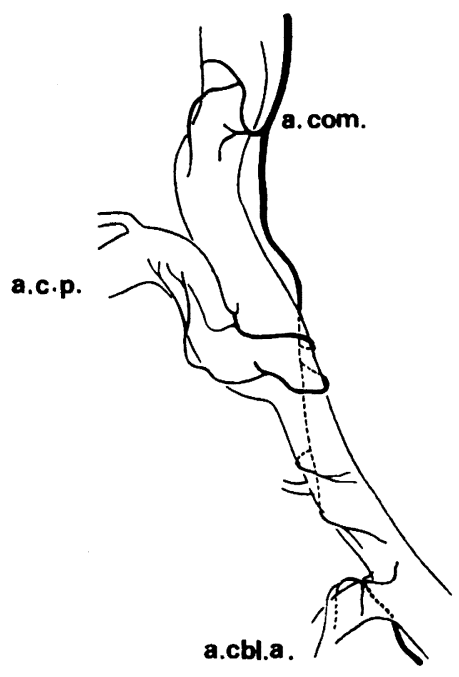

$\mathbf{R}$

Text-Fig. 2. Sketches showing the perivascular sympathetic nerve supply of the original part of the posterior cerebral and anterior cerebellar arteries. a. com. : Posterior communicating artery, a. c. p. : posterior cerebral artery, a. cbl. a. : anterior cerebellar artery.

Table 5. Communication between the terminal nerve fibers from the vertebral plexus and the posterior flows of the internal carotid plexus.

\begin{tabular}{lccc} 
& \multicolumn{2}{c}{ Anastomosis } & Total \\
& + & - & \\
\hline Right & 3 & 5 & 8 \\
Left & 6 & 2 & 8 \\
\hline
\end{tabular}

the following order. First, the caudal branch of the internal carotid artery connects with the terminal branch of the basilar artery extended from the vertebral artery in the early embryonic stage. Then, in the later stages, the network of medial branches arising from the bilateral anterior cerebral artery forms a single or double communicating artery or a common trunk to join with its fellow. Finally, the circle becomes complete. Thus, considerable variation is found in these communicating portions of the circle. For example, Puchades-Orts et al. (1975) reported that circles accompanied with variations were found in $87 \%$ of 62 human specimens, and variations in the portion of the communicating artery alone were found in $58 \%$ of the specimens. A compatison of the shape of the circles examined by the present author with that of circles from other studies is given in Table 6. In the anterior part of the closed circle, it is generally found that the bilateral anterior cerebral arteries join with the common trunk in the case of polecats, mice and golden-hamsters (Wiland, 1973, 1976; Ueshima \& Suenaga, 
Table 6. A comparison of the shape in the communicating portions of the cerebral arterial circle and a complete ratio $(\%)$.

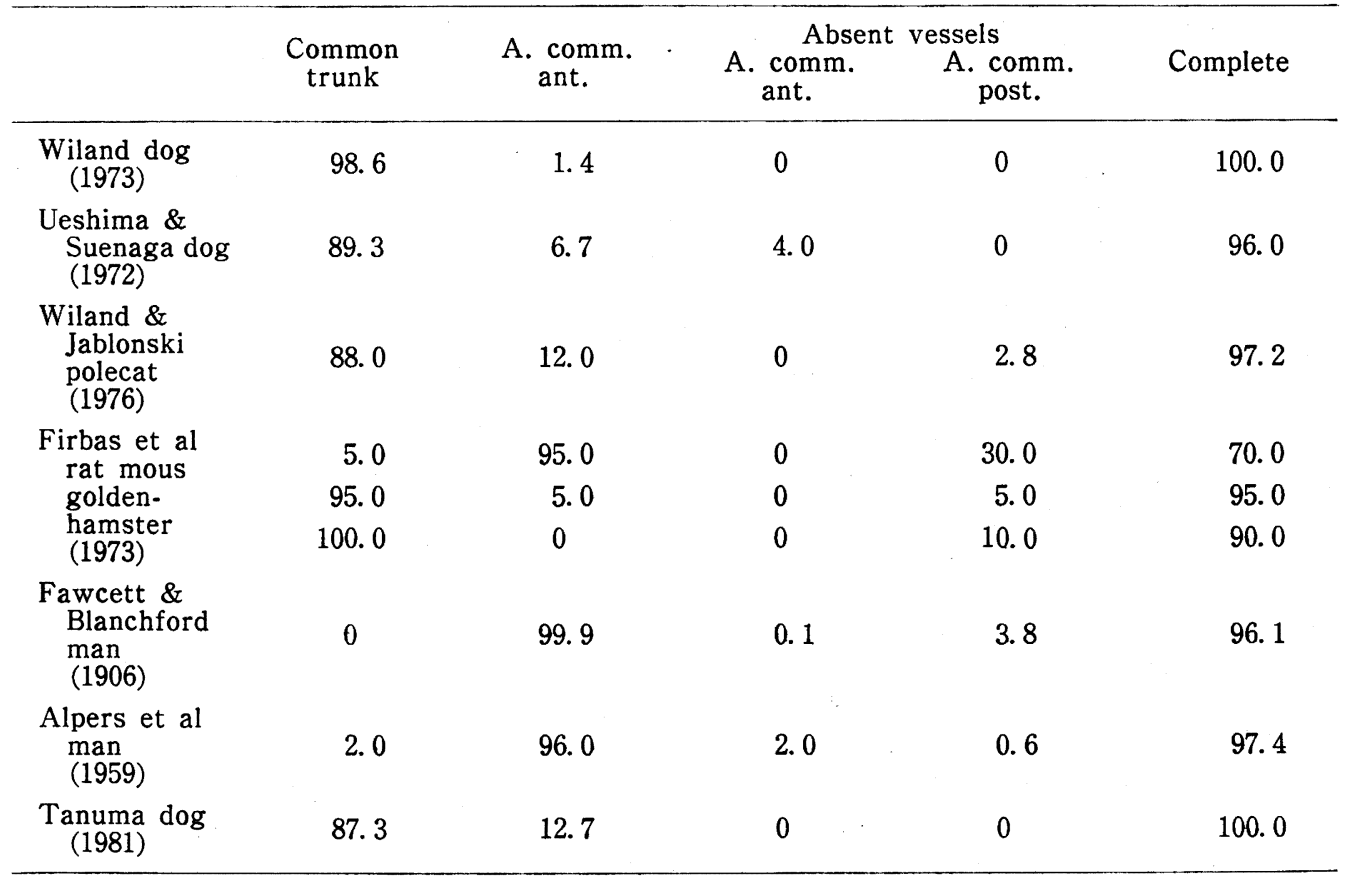

1972a, b; Firbas et al., 1973). Such a connected pattern, which closes the anterior part of the circle in the anterior communicating artery, has frequently been reported previously in in the dog. In the present study, such cases of a common trunk amounted to $87.3 \%$, although this value was not so high as those of Wiland $(94.2 \%)$ or Ueshima \& Suenaga (89.3\%). Moreover, cases possessing the anterior communicating artery amounted to $12.7 \%$ in the present study. The value obtained by the author represents a higher ratio than those of Wiland $(1.4 \%)$ or Ueshima \& Suenaga $(6.7 \%)$. In dogs, the posterior part of the circle shows exceedingly little variation compared to the anterior part. Insofar as the author was able to examine, the value for the variation in the asymmetry of the diameter of the anterior cerebral artery (14.5\%) and of the variation in the united shape of the bilateral anterior cerebral arteries (12.7\%) in the anterior part of the circle, represented a higher ratio than the value (12.7\%) for the variation (Fig. 1f, g, v, w) in the posterior part. It is conjectured from these findings and the descriptions given by many other authors, that animals possessing a strongly developed posterior communicating artery tend to show little variation, whereas such animals as have a tiny posterior communicating artery tend to show much variation in the posterior part of the circle (Fig. 1; Table 6).

The present findings for the divergent patterns of the internal carotid artery were approximately in accord with the descriptions of Ueshima \& Suenaga. The pattern of divergence in other mammals including man is not so variable as that in the dog. In mammals like man, the monkey, rabbit, cat, goat and ox, it gener- 
ally agrees with the second type of the dog (see above).

There is much variation in the anterior choroidal artery within the main arteries which arise from the arterial circle. In general, this artery is said to arise from the middle cerebral artery. A description of its origin in the dog has been given by Ueshima \& Suenaga (1972), Hatta (1936) and Habermehl (1973). The origin has also been studied in man by Beevor (1907), Carpenter et al. (1954), Otomo (1965), Herman et al. (1966) and Saeki \& Rhoton (1977). Table 7 gives a comparison of the position of origin of the anterior choroidal artery as studied by the author and by the above-mentioned workers. Although there is more or less variation in the original position of the anterior choroidal artery in man, it generally arises from the internal carotid artery. In dogs, it arises mostly from the middle cerebral artery (Ueshima \& Suenaga: $83.4 \%$, Hatta : $95.0 \%$, Wiland: $93.4 \%$, Tanuma : $68.2 \%$ ). Cases in which it arises from the posterior communicating and the internal carotid artery are also frequently found, as shown in Table 7. On the other hand, Habermehl has reported that it ramified from the anterior cerebral artery. The author did not observe such a divergent pattern.

The double posterior cerebral and anterior cerebellar arteries met with each other in $1.8 \%$ on the left side, and the double anterior cerebellar arteries also met in $1.8 \%$ on the right side. Wiland \& Jablonski (1976) have reported that these arteries occur in ruminants as a rule, but they originate with one branch in dogs.

The internal ethmoidal artery derived from the distal part of the anterior cerebral artery. However, Habermehl (1973) has reported that it does arise from the callosal corporal artery. The author did not find such a case.

Insofar as the author was able to investigate, the frequencies at which the diameters of the arteries on the left side were larger than those of the arteries on the right, showed a high value except in the case of the intecnal ethmoidal artery. However, Stopford (1916), Nagai (1933)

Table 7. Arteries of origin of the anterior choroidal artery (\%).

\begin{tabular}{lcccccc}
\hline Author, Year & $\begin{array}{c}\text { A. car. } \\
\text { int. }\end{array}$ & $\begin{array}{c}\text { Bifurcation } \\
\text { A. car. } \\
\text { int. }\end{array}$ & $\begin{array}{c}\text { A. cer. } \\
\text { med. }\end{array}$ & $\begin{array}{c}\text { A. comm. } \\
\text { post. }\end{array}$ & $\begin{array}{c}\text { A. cer. med. } \\
\text { \& A. comm. } \\
\text { post. }\end{array}$ & Absent \\
\hline $\begin{array}{l}\text { Beevor man } \\
\quad \text { 1907 }\end{array}$ & 100.0 & 0 & 0 & 0 & 0 & 0 \\
$\begin{array}{l}\text { Carpenter et al } \\
\text { man 1954 }\end{array}$ & 76.6 & 3.3 & 11.7 & 6.7 & 0 & 1.7 \\
$\begin{array}{l}\text { Otomo man 1965 } \\
\text { Herman et al }\end{array}$ & 99.2 & 0.4 & 0 & 0.4 & 0 & 0 \\
$\quad$ man 1966 & 85.0 & 7.0 & 8.0 & 0 & 0 & 0 \\
$\begin{array}{l}\text { Saeki \& Rhoton } \\
\text { man 1977 }\end{array}$ & 100.0 & 0 & 0 & 0 & 0 & 0 \\
$\begin{array}{l}\text { Hatta dog 1936 } \\
\text { Ueshima \& }\end{array}$ & 5.0 & 0 & 95.0 & 0 & 0 & 0 \\
$\quad \begin{array}{l}\text { Suenaga dog } \\
\text { 1972 }\end{array}$ & 1.3 & 3.3 & 83.4 & 8.0 & 4.0 & 0 \\
$\begin{array}{l}\text { Wiland dog 1973 } \\
\text { Tanuma dog 1981 }\end{array}$ & 0 & 0 & 93.4 & 6.6 & 0 & 0 \\
\hline
\end{tabular}


and Kondo (1936) reported no such tendency in man.

It is interesting to consider whether the posterior cerebral artery belongs to the vertebral or the internal carotid system functionally or morphologically. It has generally been said in man that the posterior cerebral artery recieves its blood from the vertebral arterial system. Certainly, the diameter of the terminal branch of the basilar artery in examined human specimens was larger than that of the posterior communicating artery in $72.5 \%$ with a mean difference of $0.146 \mathrm{~cm}$ on the right side, and in $67.5 \%$ with a mean difference of $0.140 \mathrm{~cm}$ on the left. It is clear from the above data that the vessel functionally receives its blood from the vertebral system in man. On the other hand, in the dog, the diameter of the terminal branch of the basilar artery was larger than that of the posterior communicating artery in $86.0 \%$ on the right side and in $94.0 \%$ on the left. The difference in the diameters of the two arteries averaged $0.028 \mathrm{~cm}$ in the former case and $0.025 \mathrm{~cm}$ in the latter. Although in the dog the posterior cerebral artery receives its blood from the vertebral and the internal carotid system, judging from the above facts it is supplied by the vertebral system rather than by the internal carotid system. It is difficult to say of the dog therefore that it functionally belongs entirely to the vertebral system as in the case of man.

In the 50 investigated dogs, a correlation was observed between the diameter of the posterior cerebral artery and that of the posterior communicating artery, and between the diameter of the posterior cerebral artery and that of the terminal branch of the basilar artery. However, in the human examined specimens, a correlation was found only between the diameter of the posterior cerebral artery and that of the posterior communicating artery on the right side, and between the diameter of the posterior cerebral artery and that of the terminal branch of the basilar on the left. The coefficient of correlation in the dog had a higher value than that in the human specimens. Based on the above findings, it is conjectured that the relation between the diameter of the posterior cerebral artery and that of the posterior communicating artery, and between the diameter of the terminal branch of the basilar artery and that of the posterior cerebral artery, is for more stable in the dog than in man.

Recently, the innervation of the cerebral basal arteries has been studied in various regions (Wasano, 1979; Borodulya \& Pletchkaea, 1976). The author investigated the sympathetic innervation of the vessels to clarify the origin of the posterior cerebral artery morphologically. In 1936, Williams described the perivascular innervation of the cerebral basal arteries of the human brain. The present results are essentially the same as those of Williams. Namely, the perivascular sympathetic nerve fibers fibers from the superior cervical ganglion are distributed to the lateral and anterior part of the circle which consists of the posterior cerebral, the posterior communicating, the anterior choroidal, the middle cerebral and the anterior cerebral artery. On the other hand, the sympathetic nerve fibers from the stellate ganglion which run in the cranial direction with the basilar artery can be traced to near the origin of the posterior cerebral artery. Anastomoses are found near the origin of the posterior cerebral artery between the nerve fibers from the stellate ganglion and those from the superior cervical ganglion. However, the nerve fibers from the stellate ganglion do not reach the posterior cerebral artery. It is generally said that the nerve supply of any tissue follows that tissue from its ontogenic point of origin. In addition, 
Shellshear (1920) has claimed that the distribution of arteries definitely obeys the ontogenic and phylogenetic relations. Certainly, the vertebral arterial system is distributed to the hindbrain and the internal carotid arterial system to the forebrain and the midbrain, in lower vertebrates. However, since in mammals in the advanced stage the posterior part of the cerebral hemispheres generally expands strongly backwards over the midbrain, the posterior cerebral artery of the caudal division of the internal carotid artery extends to supply the increased posterior part of the cerebral hemispheres and satisfies its increased functional demand. The relations which huve been claimed by Shellshear (1920) can be applied to mammals until these stages. Then, the posterior cerebral artery which anastomoses with the terminal branch of the basilar artery changes its source of blood flow from the internal carotid arterial system to the vertebral arterial system. The phenomenon underlying this change can be explained by Abbie's claim that "the vessels reach to the distributions through the nearest course". The sympathetic innervation of the vessels of the circle and the above discussion confirm that the posterior cerebral artery derives from the internal carotid artery.

\section{References}

1) Abbie, A.A.: The clinical significance of the anterior choroidal artery. Brain. $56: 233-246,1933$.

2) Abbie, A. A.: The morphology of the fore-brain arteries, with especial reference to the evolution of the basal ganglia. J. Anat. 68 : 433-470, 1934.

3) Beevor, C. E.: Original arteries and clinical cases: The cerebral arterial supply. Brain 30: 403-425, 1907.

4) Borodulya, A. V. \& Pletchkova, E. K. : Cholinergic innervation of vessels of the base of the brain. Acta anat. 96:135-
147, 1976.

5) Burda, D. J. : Development of intracranial arterial patterns in turtles. J. Morph. 116: 171-188, 1965.

6) Carpenter, M. B., Noback, C.R. \& Moss, M.L.: The anterior choroidal artery: Its origins, course, distribution, and variations. Arch. Neurol. Psychiat. 71 : 714-722, 1954.

7) Fawcett, E. \& Blachford, J. V.: The circle of Willis : An examination of 700 specimens. J. Anat. 15:63-70, 1906.

8) Firbas, W., Sinzinger, H. \& Schlemmer, M.: Über den Circulus arteriosus bei Ratte, Maus und Goldhamster. Anat. Histol. Embryol. 2: 243-251, 1973.

9) Getty, R.: Sisson and Grossman's The anatomy of the domestic animals. 5th. ed. vol. 2 : 1611-1617, 1975.

10) Gillilan, L.A.: A comparative study of the extrinsic and intrinsic arterial blood supply to brains of submammalian vertebrates. J. Comp. Neur. 130: 175-196, 1967.

11) Habermehl, K.-H.: Zur Topographie der Gehirngefässe des Hundes. Anat. Histol. Embryol. 2: 327-353, 1973.

12) Hatta, S.: Study of the brain arteries. Igaku Kenkyu 10: 1087-1236, 1303-1503, 1936.

13) Herman, L. H., Fernando, O. U. \& Gwurdjian, E.S.: The anterior choroidal artery: an anatomical study of its area of distribution. Anat. Rec. 154: 95-102, 1966.

14) Hofmann, M.: Zur vergleichenden Anatomie der Gehirn-und Rückenmarksarterien der Vertebraten. Z. Morph. Anthropol. 2: 247-322, 1900 .

15) Jablonski, R. \& Wiland, C.: Variation of the arteries of the brain in sheep. Folia Morph. (Warsz.) $32: 339-347,1973$.

16) Kanan, C.V.: The cerebral arteries of Camelus dromedarius. Acta anat. $77: 605-$ 616, 1970.

17) Kaplan, H. \& Ford, D. H.: The brain vascular system. 1st. 6-26, 64. Elsevier Pub. Co. Amsterdam, Lonodon, New York, 1966.

18) Kassel, N. F. \& Langfitt, T. W.: Variations in the circle of Willis in macaca mulatta. Anat. Rec. 152: 257-264, 1965. 
19) Kondo, M.: Studien über die Arterien der Hirnbasis der Koreaner. Acta Anat. Nippon. 9 : 510-527, 1936.

20) Lierse, W.: Über die Beeinflussung der Hirnangioarchitektur durch die Morphogenese. Acta Anat. 53 : 1-54, 1963.

21) Miller, M.E., Christensen, G.C. \& Evans, H. E. : Anatomy of the dog, 1st. ed. 312319. W. B. Saunders Co. Ltd. Philadelphia, London, 1964.

22) Moffat, D. B.: The development of the hind-brain arteries in the rat. J. Anat. Lond. 91 : 25-39, 1957.

23) Moffat, D. B.: The development of the anterior cerebral artery and its related vessels in the rat. Am. J. Anat. 108: 17-29, 1961.

24) Moffat, D.B.: The development of the posterior cerebral artery. J. Anat. 95 : 485-494, 1961.

25) Moffat, D.B.: The embryology of the arteries of the brain. Ann. Roy. Coll. Surg. Eng. 30: 368-382, 1962.

26) Nagai, H.: Anatomical and Pathological studies of cerebral basal arteries. J. Nippon. Med. Sch. 4 : 1533-1570, 1933.

27) Otomo, E.: The anterior choroidal artery. Arch. Neurol. 13 : 656-658, 1965.

28) Puchades-Orts, A., Mombela-Gomez, M. \& Ortuno-Pacheco, H. : Variation in form of circle of Willis: Some anatomical and embryological considerations. Anat. Rec. 185 : 119-124, 1976.

29) Saeki, N. \& Photon, A. L.: Microsurgical anatomy of the upper basilar artery and the posterior circle of Willis. J. Neurosurg. 46 : 563-578, 1977.

30) Shellshear, J.L.: The basal arteries of the forebrain and their functional significance. J. Anat. $55: 27-35,1920$.

31) Stopford, J.S.B.: The arteries of the pons and medulla oblongata. J. Anat. 50 : 131-164, 1916.

32) Tanuma, K.: On the morphological study of the avian's brain artery. J. Nippon. Med. Sch. 45: 40-58, 1978.

33) Ueshima, T. \& Suenaga, Y.: Arteries of the basal region of the brain in the dog. I. Origins of main arteries. J. Faculty Agricult. Tottori Univ. 52: 38-46, 1972.

34) Ueshima, T. \& Suenaga, Y.: Arteries of the basal region of the brain in the dog. II. Anatomical structures and courses of main arteries. J. Faculty Agricult. Tottori Univ. 52: 47-56, 1972.

35) Wasano, T.: Comparative anatomy of the blood vessel supply of the vertebrate's brains. Adv. Neur. Sci. 10 : 530-534, 1966.

36) Wasano, T.: Innervation of the cerebral blood vessels of vertebrates. Acta. Anat. Nippon. 54 : 65-84, 1979.

37) Watts, J. W.: A comparative study of the anterior cerebral artery and the circle of Willis in primates. J. Anat. 68: 534$550,1933$.

38) Wiland, C. : Variation of the basal arteries. of the brain in dogs. Folia Morph. (Warsz) $32: 63-70,1973$.

39) Wiland, C. \& Jablonski, R.: Variation in basal arteries of the brain in polecat (Mustela putorius putorius L.). Anat. Anz. 140: 498-502, 1976.

40) Williams, D. J.: The origin of the posterior cerebral artery. Brain 59 : 175180, 1936. 


\section{Explanation of Figures}

\section{Plate I}

Fig. 1. The most general shape of the cerebral arterial circle.

Fig. 2. A circle having a single anterior communicating artery. The arrow indicates the poistion of the anterior communicating artery.

Fig. 3. A circle having a double anterior communicating artery. The anterior communicating artery is indicated by an arrow.

Fig. 4. Asymmetry in the diameter of the anterior cerebral artery. The anterior cerebral artery on the right side is thicker than that on the left. The arrows indicate the bilateral anterior cerebral arteries. 

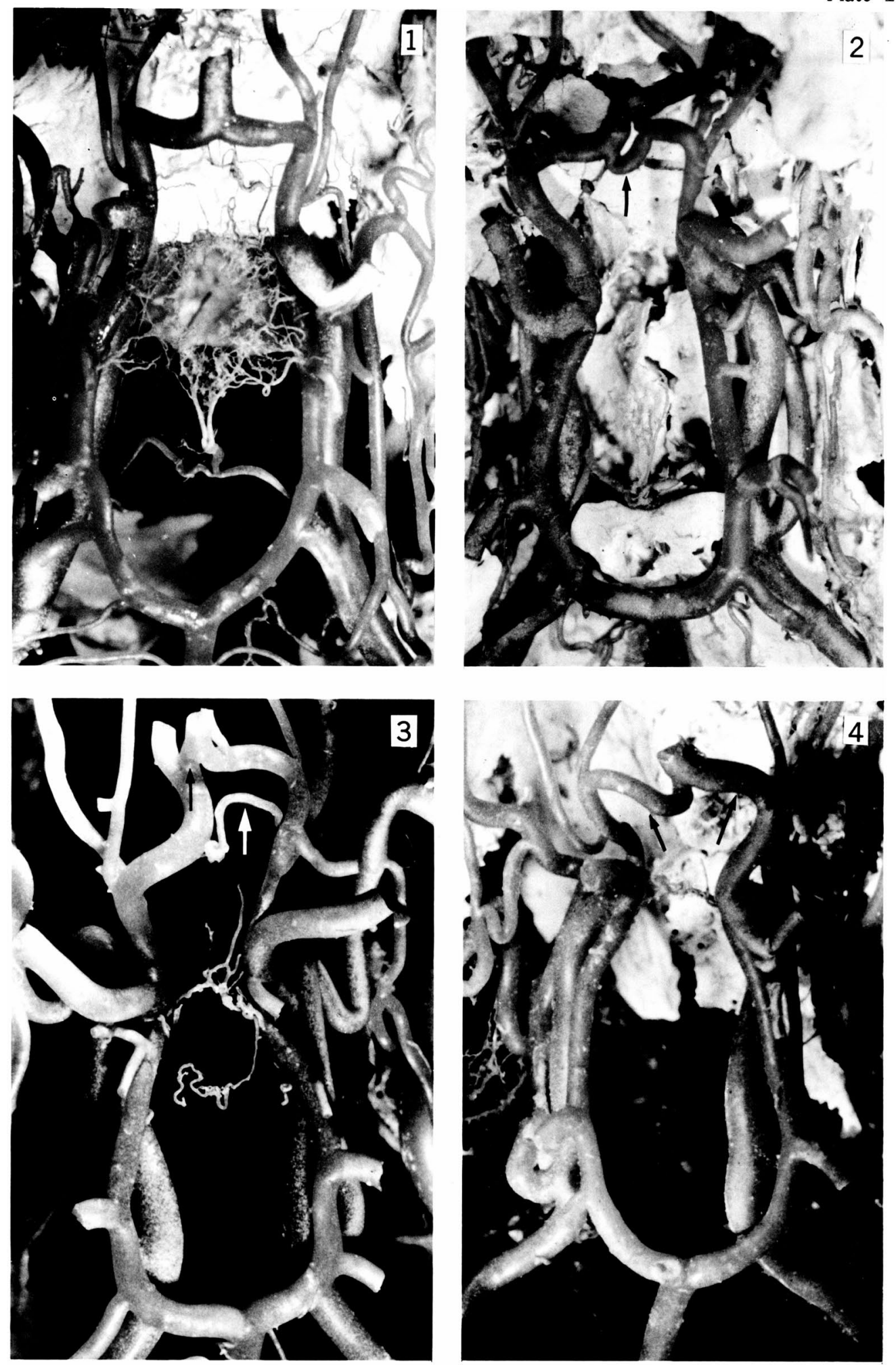

K. Tanuma 


\section{Plate II}

Fig. 5. A circle having a double anterior cerebellar artery. Each of the anterior cerebellar arteries is indicated by an arrow.

Fig. 6. Example an island like a button-hole near the position of origin of the posterior cerebral artery. The arrow indicates the island.

Fig. 7. Perivascular sympathetic innervation of the original portion of the posterior cerebral artery. Arrows indicate the anastomoses between the basilar nerve plexus and the internal carotid plexus. a. com. p.: Posterior communicating artery, a. c. p. : posterior cerebral artery. 

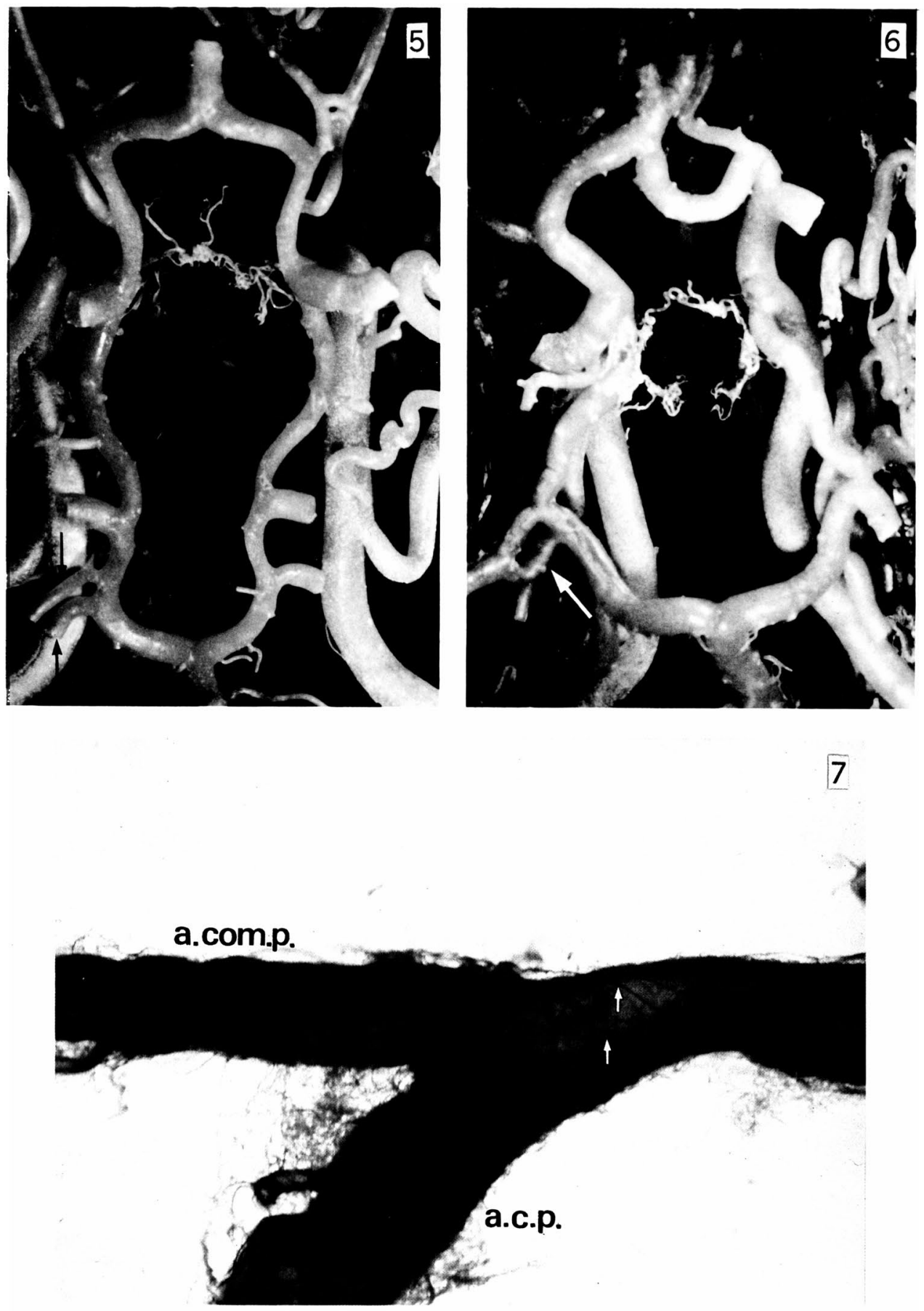